\title{
Estimation of infiltration rate, run-off and sediment yield under simulated rainfall experiments in upper Pravara Basin, India: Effect of slope angle and grass-cover
}

\author{
Veena U Joshi* and Devidas T Tambe \\ Department of Geography, University of Pune, Pune 411 00\%, India. \\ *e-mail:vujoshi@unipune.ernet.in
}

The main objective of this study is to measure the effect of slope and grass-cover on infiltration rate, run-off and sediment yield under simulated rainfall conditions in a badland area located in the upper Pravara Basin in western India. An automatic rainfall simulator was designed following Dunne et al (1980) and considering the local conditions. Experiments were conducted on six selected experimental fields of $2 \times 2 \mathrm{~m}$ within the catchment with distinct variations in surface characteristics - grass-covered area with gentle slope, recently ploughed gently sloping area, area covered by crop residue (moderate slope), bare badland with steep slope, gravelly surface with near flat slope and steep slope with grass-cover. The results indicate subtle to noteworthy variations amongst the plots depending on their slope angle and surface characteristics. An important finding that emerges from the study is that the grass-cover is the most effective measure in inducing infiltration and in turn minimizing run-off and sediment yield. Sediment yields are lowest in gently sloping grass-covered surfaces and highest in bare badland surfaces with steep slopes. These findings have enormous implication for this area, because over $2 / 3$ area is characterized by bare and steep slopes.

\section{Introduction}

Controlled experiments under simulated rainfall for studying infiltration and soil erodibility are not a new concept amongst the scientists concerned with soil erosion and land management. However, most of these experiments have been conducted in technologically advanced nations where there is abundant availability of capital, skilled labour and water resources. Although rainfall simulation experiments to evaluate rainfall-run-off relations and soil erosion have been overwhelmingly conducted in Europe and North America; similar studies are practically unknown from South Asia, particularly from the semi-arid region. In India also, very few studies have been reported that focused on infiltration, run-off and erosion studies based rainfall simulator experiment (Bhardwaj and
Singh 1992; Singh et al 1999). Rawat et al (1992), Rawat and Rawat (1994) and Rawat and Rai (1997) have measured run-off and sediment yield over a period of 2-3 years from micro-watersheds in Kumaun Himalaya under the natural rainfall conditions but studies based on simulated rainfall are very rare in the country.

In an agriculture-based country like India, where there is ever increasing pressure of population on land and water resources, such field experiments would be of great help in the proper understanding of the widespread problem of land degradation and soil erosion. In a data-poor country like India, controlled field and/or laboratory experiments under simulated rainfall have several advantages. There are formidable practical difficulties in carrying out such long-term monitoring experiments under natural conditions

Keywords. Rainfall simulator; infiltration; sediment yield; badland; grass-covered surface; experimental plots. 


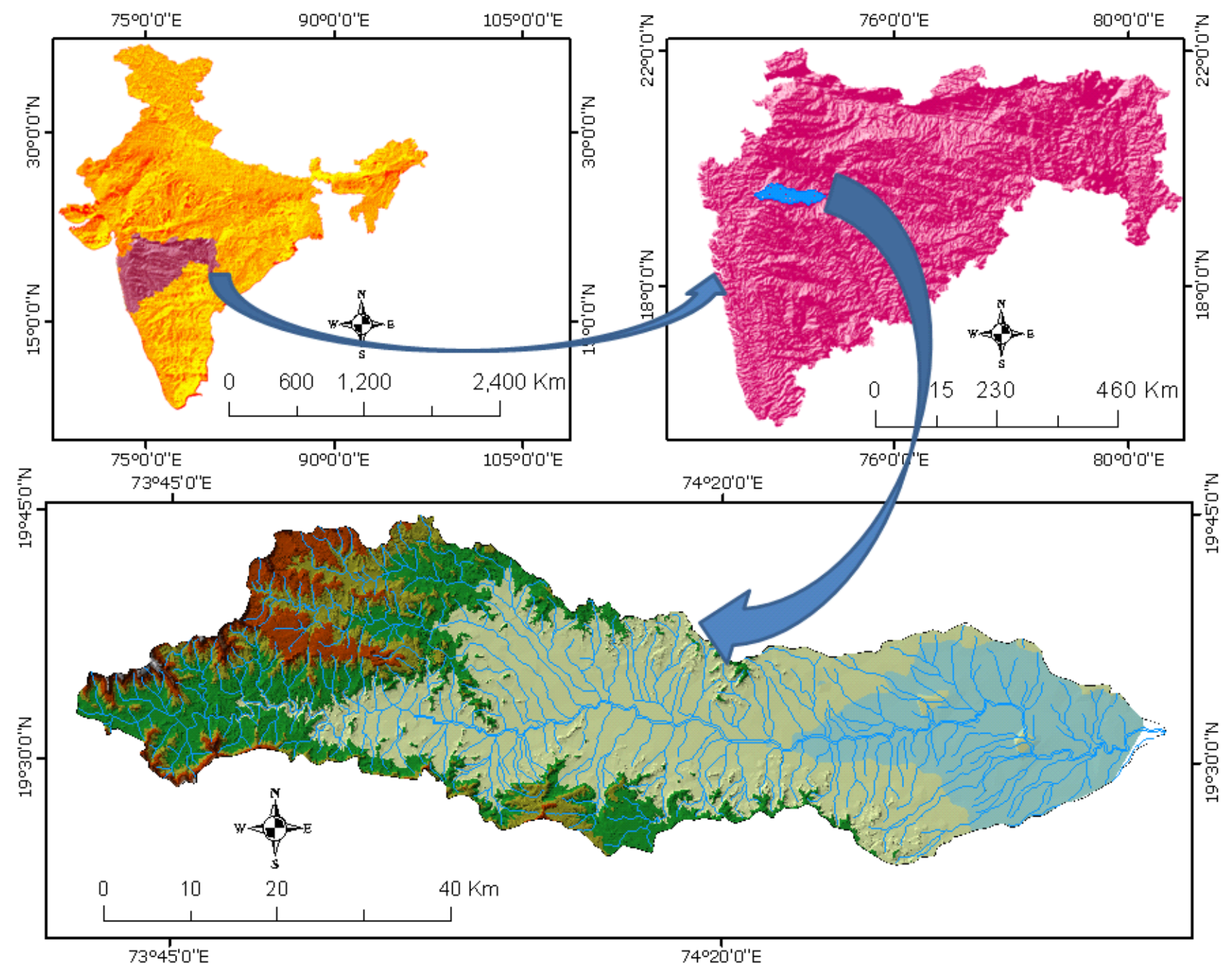

Figure 1. Location map of the study area.

due to anthropogenic disturbances. Therefore the present investigation aims at studying the control of various land uses on soil erosion and sediment yield under the simulated rainfall conditions.

The main objective of this study was to measure the effect of slope and grass-cover on run-off, infiltration and sediment yield under simulated rainfall conditions in badland area of the upper Pravara Basin.

\section{Study area}

The study area is located in a small catchment within the Pravara River Basin. The Pravara River is a tributary of Godavari River which drains into the Bay of Bengal (figure 1). The area is characterized by Quaternary alluvium underlain by basalts of Cretaceous-Eocene age (Kale and Rajaguru 1987). The alluvial deposits are mostly confined to the wide valley of the Pravara River and its major tributaries. Wherever the deposits are thick and areally extensive, they are covered by a dense network of gullies, resulting into a hummocky landscape akin to badlands. The sparse vegetation cover dominantly includes acacias trees, which are typical of semi-arid regions. The alluvial sediments reveal an admixture of gravel, sand silt with lesser percentage of clay (figure 2). As the geomorphic term implies, such badlands are unsuitable for any kind of economic activity and are usually the last choice until the demand for land becomes too great even to spare such unproductive areas. As a result of increasing demand for cultivated area, the 'badland' area is presently undergoing massive land levelling and reclamation for the purpose of agriculture.

The climate of the area is monsoonal, but due to its location in the rain-shadow zone of the Western Ghat the area is characterized by low average annual rainfall $(\sim 550 \mathrm{~mm})$ and high rate of evapotranspiration. Consequently, the climate of the area can be classified as semi-arid. Rainfall is concentrated within the four monsoon months 


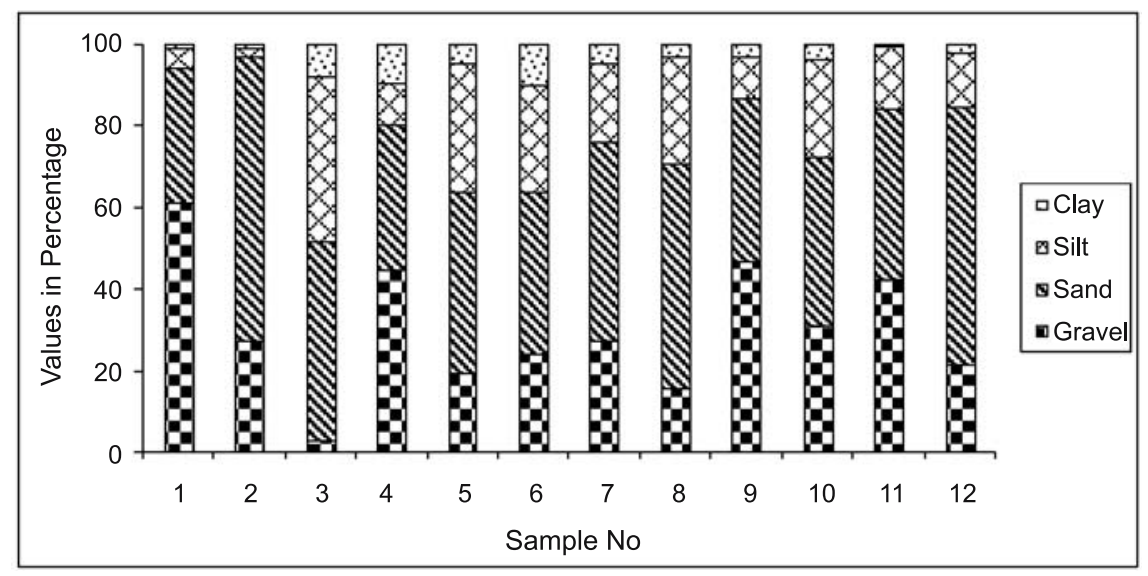

Figure 2. Grain size characteristics of the badland sediments.

(June to September). There is a long dry period following the monsoon. Though the amount of rainfall is meagre, few rainstorms with moderateto-high intensity $(>50 \mathrm{~mm} / \mathrm{h})$ occur occasionally during the monsoon season. The unconsolidated alluvial deposits are highly susceptible to erosion during such rainstorms. The erosion is primarily manifested in the form of gullies, which have a wellintegrated drainage network and have practically invaded the entire area under study.

The area under review does not have any rain gauging station or discharge gauging station. Consequently, there is no information about the rate of sediment erosion and sediment yield. In view of the extent of the badland area, the only possible way to generate information about these critical issues is to conduct experiments in the field. In the present study, therefore, it was decided to artificially simulate the rainfall over different land cover categories.

\section{The rainfall simulator}

For all the rainfall experiment studies carried out in different parts of the globe, different simulators have been used by different investigators that are designed to suit the local requirements (Tricker 1979; Dunne et al 1980; Roth et al 1985; Bowyer-Bower and Burt 1989; Exeter 1990; Bhardwaj and Singh 1992; Hignett et al 1995; Cerda et al 1997; Singh et al 1999 and Wright et al 2002 and others). Like earlier studies, in this study also while designing the simulator, several factors such as the terrain characteristics, plot size, accessibility to water sources, etc. have been taken into consideration. The rainfall simulator has been designed following Dunne et al (1980). The present simulator, however, is automatic and certain specifications have been modified to suit the present requirements. The simulator consists of a

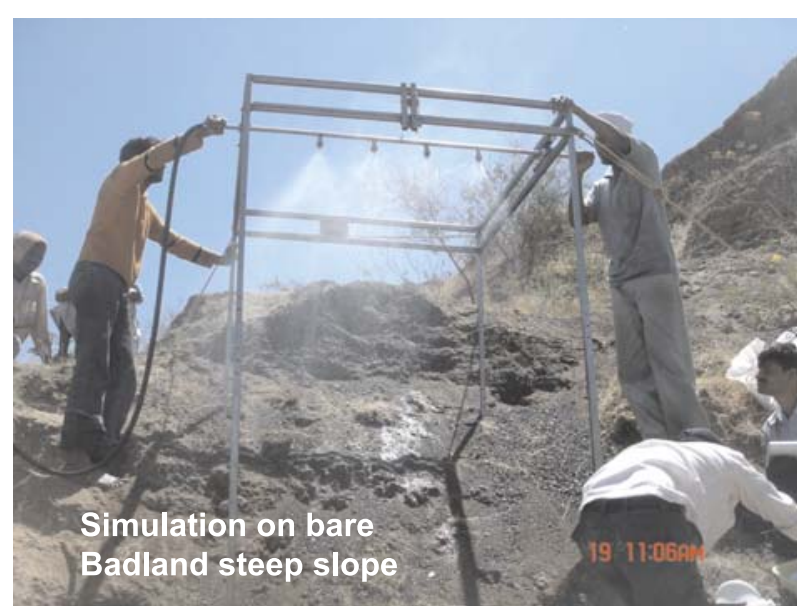

(a)

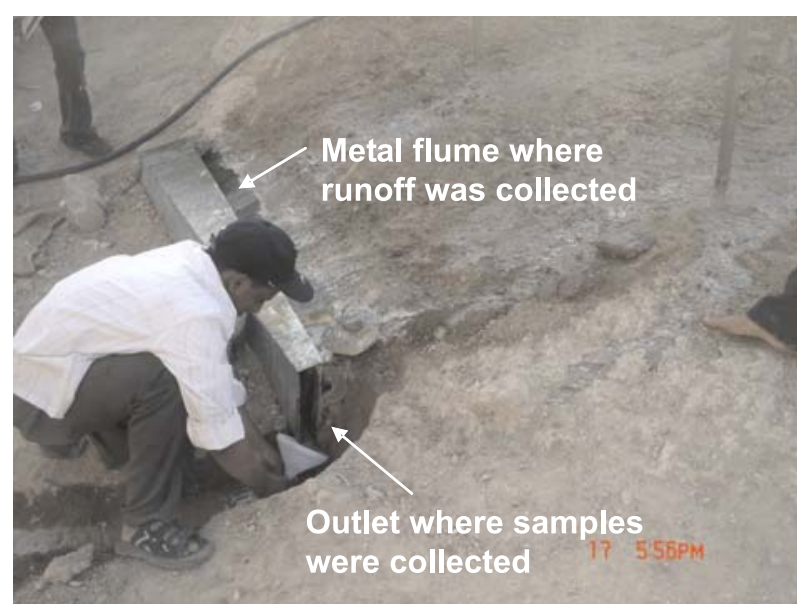

(b)

Figure 3. Rainfall simulator (a) and the metal flume (b) where run-off was collected in $290 \mathrm{ml}$ bottles.

bolted steel frame $3 \mathrm{~m}$ high (which can be adjusted according to the gradient of the surface) and is $2 \times 2 \mathrm{~m}$ in size. A steel track is suspended along the central line of the structure (figure 3a). Four nozzles are attached to a wheeled trolley $(1.2 \mathrm{~mm}$ 


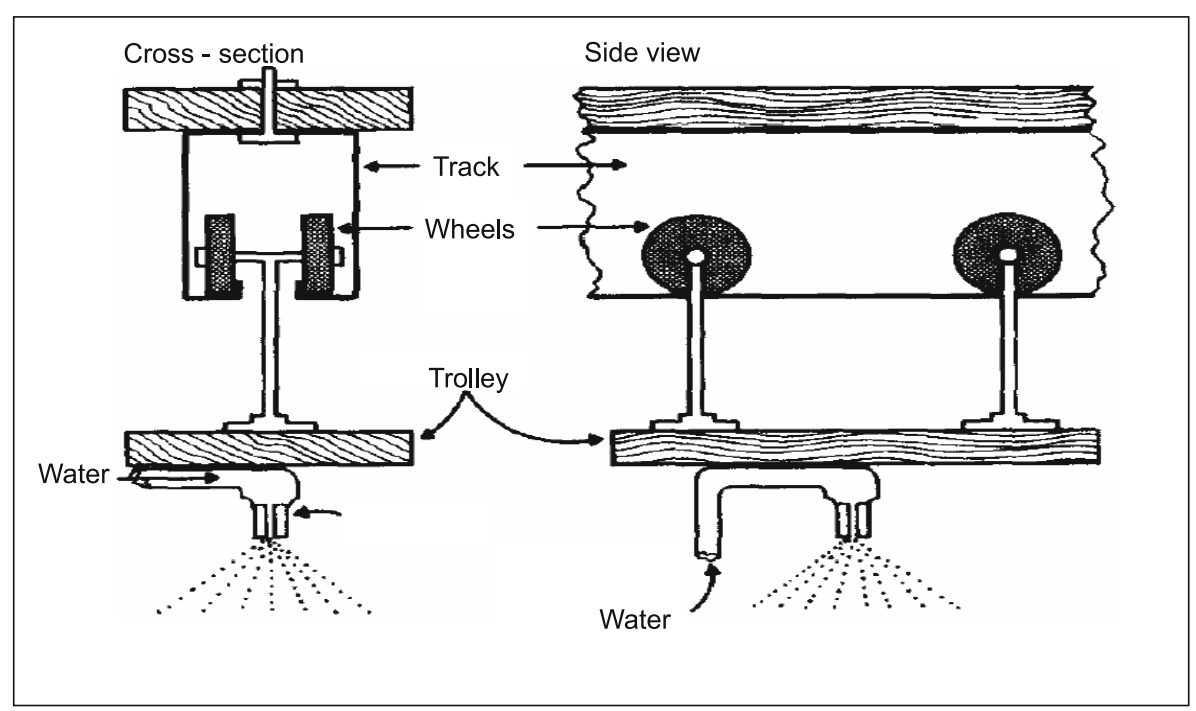

(a)

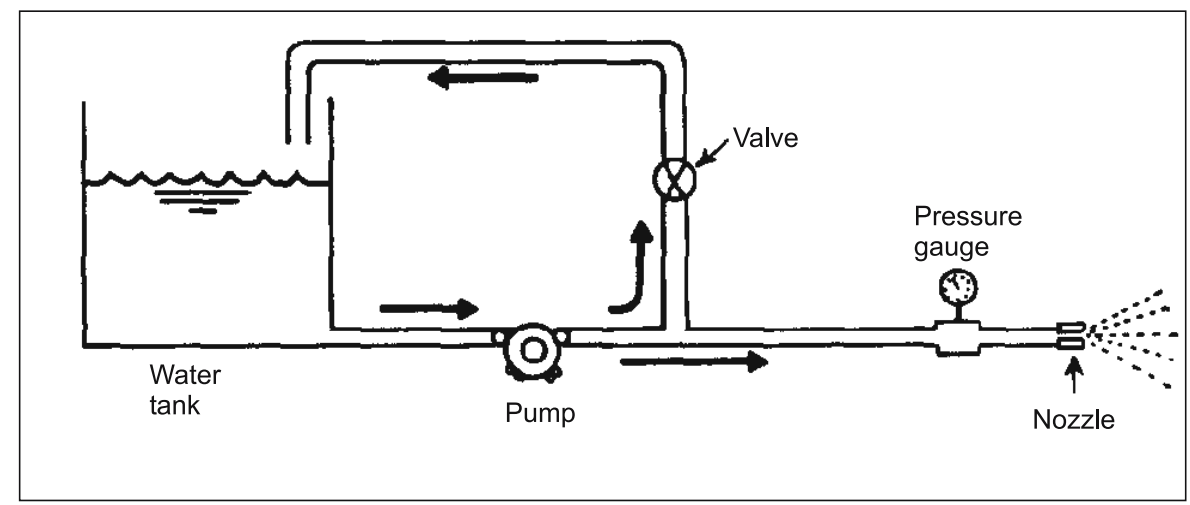

(b)

Figure 4. (a) End and side diagrams of the suspension of a spray nozzle from a trolley which moves on wheels in an overhead track running the length of the rainfall simulator. (b) Schematic diagram of the system used for supplying water to the rainfall simulator. The recirculating loop allows fine adjustment of the pressure in the line feeding the spray nozzle even if a fixed-capacity pump is used (reproduced and designed after Dunne et al 1980).

in diameter) which moves automatically along the track. The track-ends are protected with foam rubber. The trolley is made to traverse a length of $1.9 \mathrm{~m}$ in $<3$ seconds. The speed of the movement of the trolley is so adjusted to distribute uniform spray of rainfall all over the experimental plot. On windy days we shielded the plot by attaching a heavy canvas sheet on the upwind side of the steel frame. A schematic diagram of the end and side diagrams of the suspension and the system used for supplying water to the rainfall simulator has been reproduced from Dunne et al (1980) and is presented in figure 4.

Water was supplied to the nozzle from a 500-litre water tank by a 1-HP diesel pump. It suffices for 1-h experiment. The main hose pipe from the pump bifurcates into two. One line goes to the nozzle and the other is connected back to the water tank. A valve is fitted to the return pipe to adjust the pressure and flow rate of the first pipe connected to the nozzle. Repeated observations indicate that after the initial adjustment the pressure generally remains constant during the entire experiment. The nozzles were custom-made. After several trial runs and calibrations, the final simulations were carried out on six plots in the study area, to estimate the rainfall intensity vis-à-vis infiltration rate, run-off rate and sediment yield. To calculate all the above parameters standard procedures were adopted (Dunne et al 1980). The plot specifications and the results of the study are presented in the following section.

\section{The experimental plots}

In order to ensure highest possible accuracy in the estimation of the infiltration rate and the runoff, the experimental plots were designed exactly following Dunne et al (1980). At the lower end of 
each plot a sheet metal trough (figure $3 \mathrm{~b}$ ) received the run-off and sediment, and conveyed them to a collection point. The slope of the metal trough was adjusted to match with the slope of the plot. Extra care was taken so that there is no loss of run-off and sediments.

Installation of the collection trough began with the digging of a $2-\mathrm{m}$ long, $22 \mathrm{~cm}$ wide and $25 \mathrm{~cm}$ deep trench at the lower end of the experimental plot. A prefabricated metal sheet was placed in the trough (figure $3 \mathrm{~b}$ ), and was held firmly against the upslope face by backfilling the trench from all sides. The trough was designed so that when its roof lay horizontal; its floor had a gradient of $10 \%$, which proved to be sufficient to convey all eroded soil rapidly to the outlet. When the trough was firmly in place, a prefabricated sheet metal lip was installed. The lip was first bent so that it had a short limb, about $2-3 \mathrm{~cm}$ side, and a broader limb about $20 \mathrm{~cm}$ wide. The short limb was driven firmly into the soil at the upper boundary of the strip. Wetting the strip of soil before driving in the lip minimized the disturbance. In order to ensure a watertight seal between the lip and the topsoil and to prevent any erosion of the contact, a strip of plaster of Paris was used to stabilize the lip as suggested by Dunne et al (1980).

\section{Rainfall experiment}

Before the instrument was taken to the field for simulation, a final testing was conducted by simulating rain for one hour. The actual field experiments were conducted in the pre-monsoon season (May 2008). For objective site selection, various steps were followed. Since the primary goal of this study is to estimate the rates of erosion from badland areas, it was necessary to clearly identify such areas in the basin. This was achieved by undertaking supervised classification of high-resolution satellite images. For this IRSPAN and LISS III merged product images of 1997 and 2007 were analysed in ERDAS (figure 5). From the classified images, the area under badland was demarcated. The next step was to identify areas that have undergone maximum reclamation within the 10-year period. This identification was further supported by field investigations. During the field investigations, special attention was given to the existing land cover/use and the slope, before the final selection of the sites for experimental studies. Six plots having very different land use/cover were finally selected in order to estimate infiltration rate, run-off and sediment yield, and to establish the role of land use/cover and the slope. The details of the six plots are given in table 1 .

\section{Measurement of run-off and soil loss}

According to Hudson (1961), the threshold for starting erosion under the tropical rain is $30 \mathrm{~mm} / \mathrm{h}$. Therefore, during the present study, the experiments were basically designed for rainfall intensity equal to 30,50 and $75 \mathrm{~mm} / \mathrm{h}$. However, in this paper the results of experiments conducted with all the four nozzles fully opened, giving a rainfall intensity of $76.39 \mathrm{~mm} / \mathrm{h}$ (close to $75 \mathrm{~mm} / \mathrm{h}$ ) have been presented. The highest intensity value was selected to represent severe rainstorm in the area. Another reason for selecting this upper limit was that the trial experiment revealed that fluctuations in the hydrograph were minimum when experiments were conducted with the nozzles fully open. Since the purpose of the experiment was to make comparisons of runs over different land use/cover plots, the intensity value was kept constant $(76.39 \mathrm{~mm} / \mathrm{h})$ for all the experiments. Water for the experiment was obtained from the nearby wells. Samples of the run-off and sediment were collected in $290 \mathrm{ml}$ plastic bottles and the filling-time was recorded. During the 1-h experiments, samples were collected after every five minutes. Infiltration, run-off rates and sediment yield were calculated by following the standard procedures.

\section{Results}

The infiltration rate, run-off and sediment concentration plots and regression lines for all the six plots are illustrated in figure $6(\mathrm{a}$ and $\mathrm{b})$ and the summary of the results is presented in table 2 . It is evident from the figures and the table that the trends displayed by the regression lines are not totally unexpected. In general, the infiltration rates are higher and run-off is lower within the first few minutes of the commencement of the experiments. This pattern, however, reverses as the experiment progresses and continues till the end of the experiment. However, there are subtle differences in the infiltration and run-off rates amongst the plots and noteworthy differences in the sediment yields. The plot-wise results are discussed below.

Plot 1: This plot represents gently sloping areas with dense grass-cover. The scatter plot and the fitted regression line indicate that the infiltration rate is higher to begin with and continues to remain high throughout the experiment, unlike other plots. It is interesting to note that noteworthy runoff starts only after 40 minutes. This can be attributed to the ability of grasses to trap rain water and induce infiltration for a longer duration. The run-off is initiated only after the soil became completely saturated and water starts collecting 


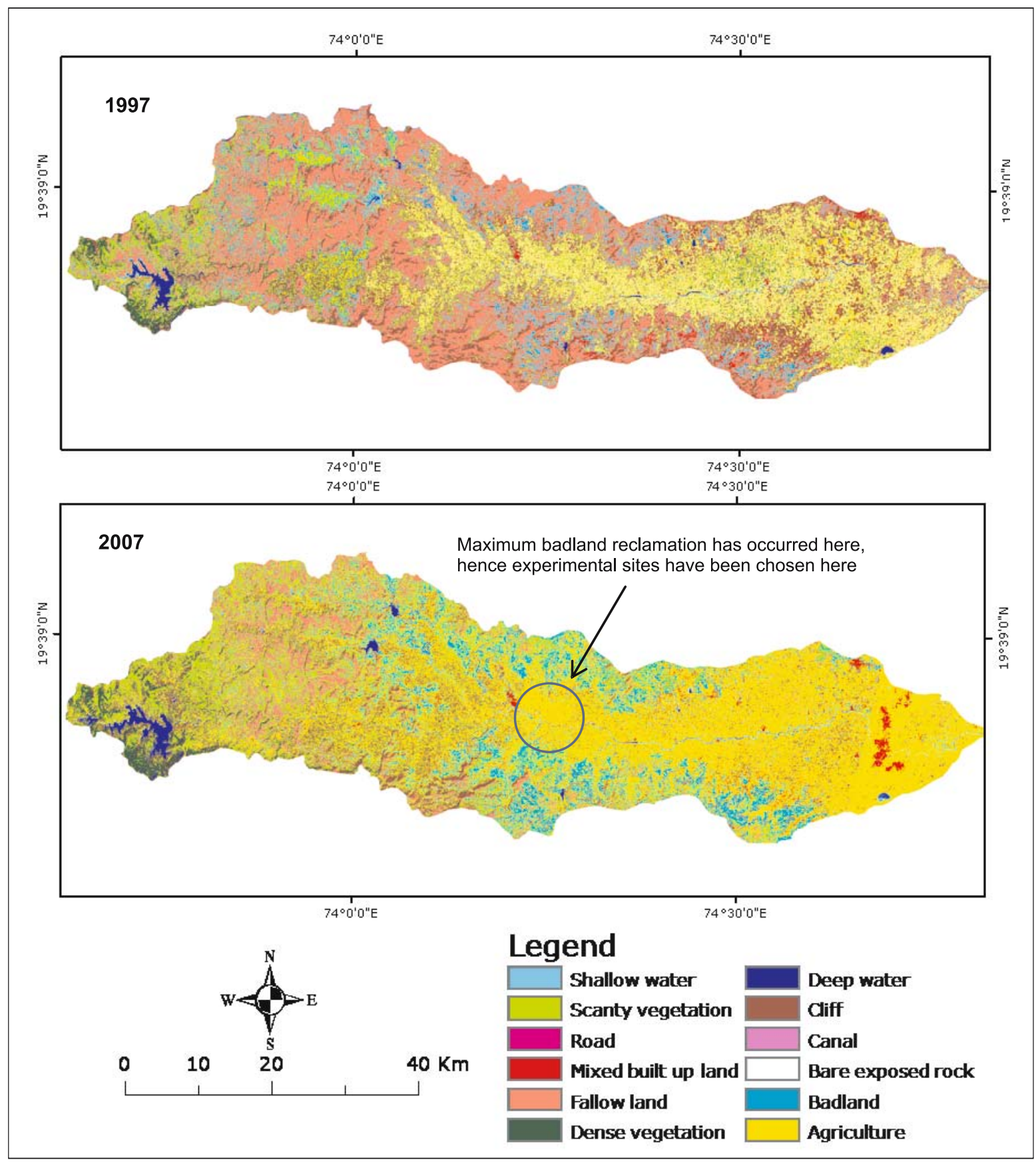

Figure 5. Supervised classified images of the year 1997 and 2007 of the study area, from where the areas of badlands have been demarcated.

Table 1. Sediment yield after one hour experiment.

\begin{tabular}{llcc}
\hline $\begin{array}{l}\text { Experiment } \\
\text { no. }\end{array}$ & \multicolumn{1}{c}{ Surface characteristics } & $\begin{array}{c}\text { Total sediment } \\
\text { loss }\left(\mathrm{gm} / \mathrm{m}^{2}\right)\end{array}$ & $\begin{array}{c}\text { Run-off } \\
(\mathrm{mm} / \mathrm{h})\end{array}$ \\
\hline 1 & Grass covered area with 20 degree slope & 62.70 & 142.23 \\
2 & Recently ploughed area with gentle slope & 345.08 & 338.10 \\
3 & Crop residue covered area (gentle slope) & 335.34 & 276.76 \\
4 & Bare badland 65 degrees slope & 2931.05 & 259.29 \\
5 & Gravel surface with moderate slope & 596.36 & 422.75 \\
6 & Steep slope with grass cover & 534.34 & 477.90 \\
\hline
\end{tabular}


over the saturated root depth. On account of high infiltration rate and low run-off, the sediment yield is minimum.

Plot 2: This plot represents recently ploughed field on gentle slope. In this area all the fields are ploughed before the monsoon. The effect of first rain on such fields can be observed very clearly in this experiment. Within five minutes after the beginning of the experiment the loose topsoil quickly became saturated and starts forming rills. There was a steady increase in the runoff until the end of the experiment with flow of the water and sediments following these rills. The hydrograph and sediment concentration curves are very identical except that the run-off increased steadily until the end of the experiment, but the sediment concentration showed a plateau roughly in the second half of the experiment. After the removal of the initial loose material, a thin crust developed that marginally slowed down the sediment removal rate. Overall, the sediment removal is relatively high in spite of the gentle slope of the plot.

Plot 3: This plot represents a field with crop residue, which has not been yet ploughed. The remaining maize stems after harvest and leaves strewn all over the fields characterize the plot. This field is located on gently sloping valley floor. The plot experiment revealed a gradual declining but relatively higher infiltration rate within the first half of the experiment. Run-off first shows a sharp rise up to 30 minutes from the commencement of the experiment. This is followed by a long period of no-change. The last 10 minutes of the experiment, however, reveal a sudden enhancement in run-off generation. This trend in run-off is difficult to explain but could be associated with the presence of organic debris on the plot surface. The reason appears to be also responsible for lower sediment removal. It therefore, appears that plots with crop residue are better protected from soil erosion during intense rainstorms.

Similar findings were presented by Bradford and Huang (1994) while studying soil loss, runoff, and infiltration using a rainfall simulator, on interrill erosion plots with and without residue cover in central Illinois. The results of the experiment indicates that for both conventional till and no-till conditions, removing surface residue significantly decreased infiltration rates and increased soil loss. Tilling the no-till surface while
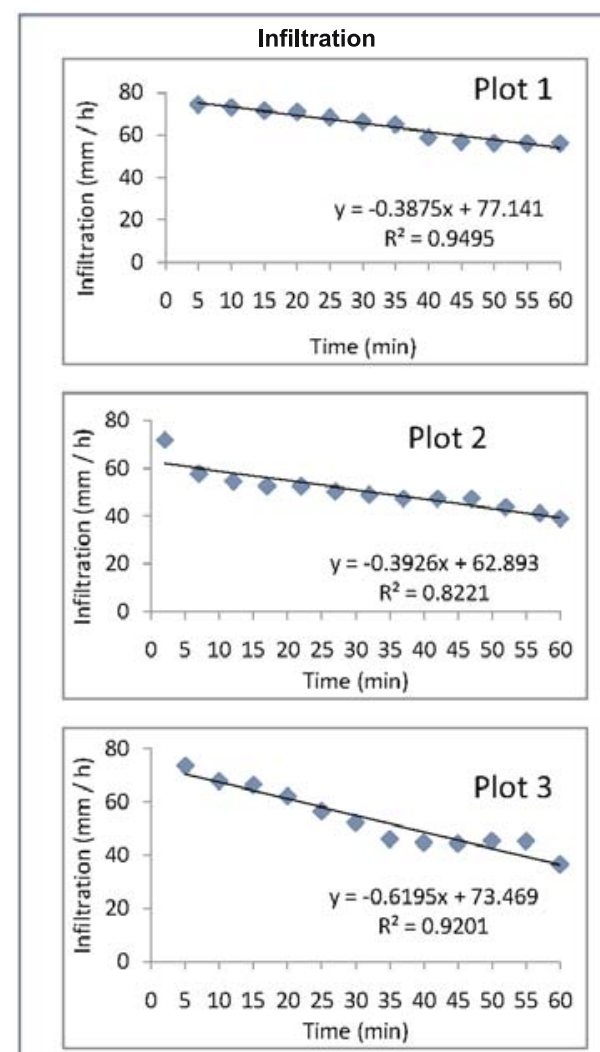

(a)
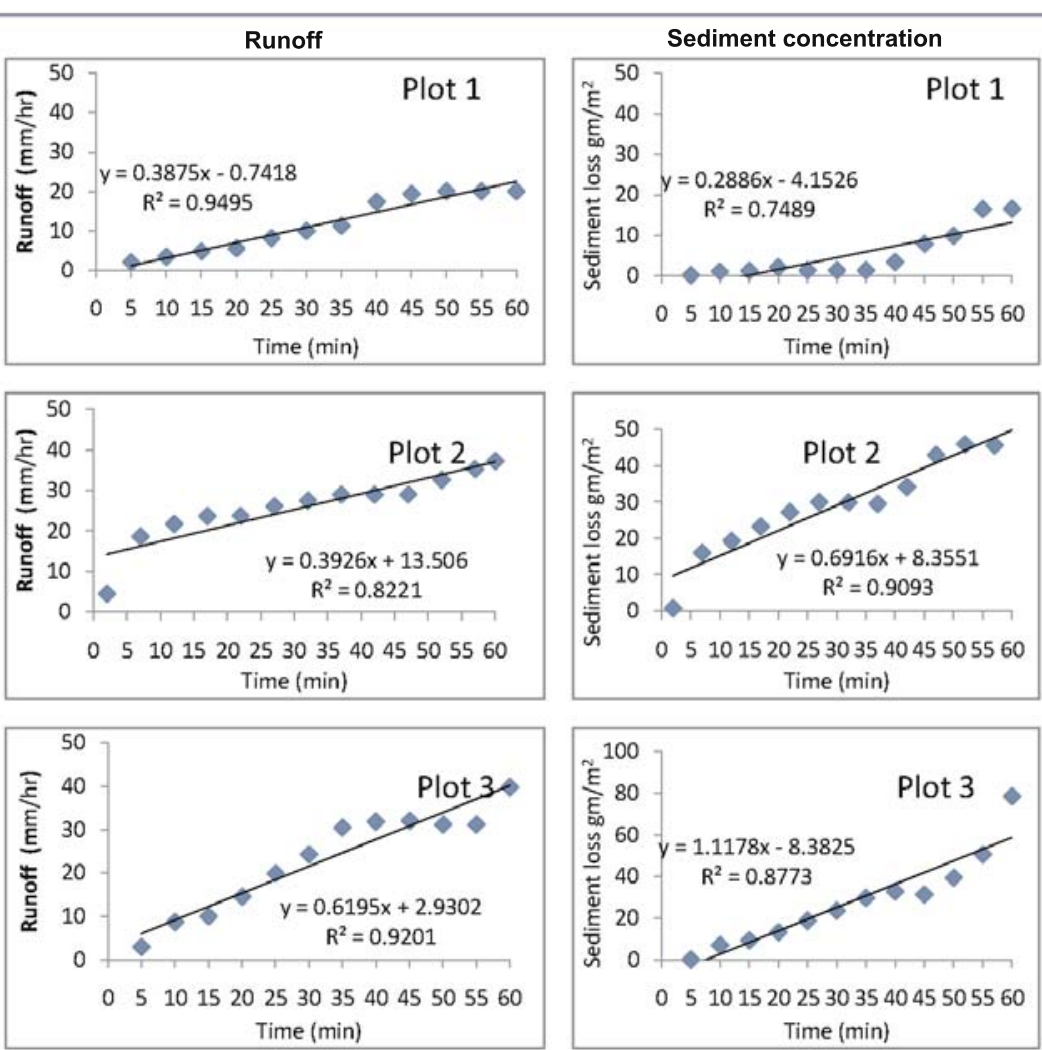

Plot 1 - Grass covered area, 20 degree slope, Plot 2 - Recently ploughed area, gentle slope, Plot 3 - Crop residue covered area, moderate slope

Figure $6(\mathrm{a}$ and $\mathrm{b})$. Scatter plots and regression lines for all the six plots, showing the relations between infiltration rates, run-off and sediment loss and time. 


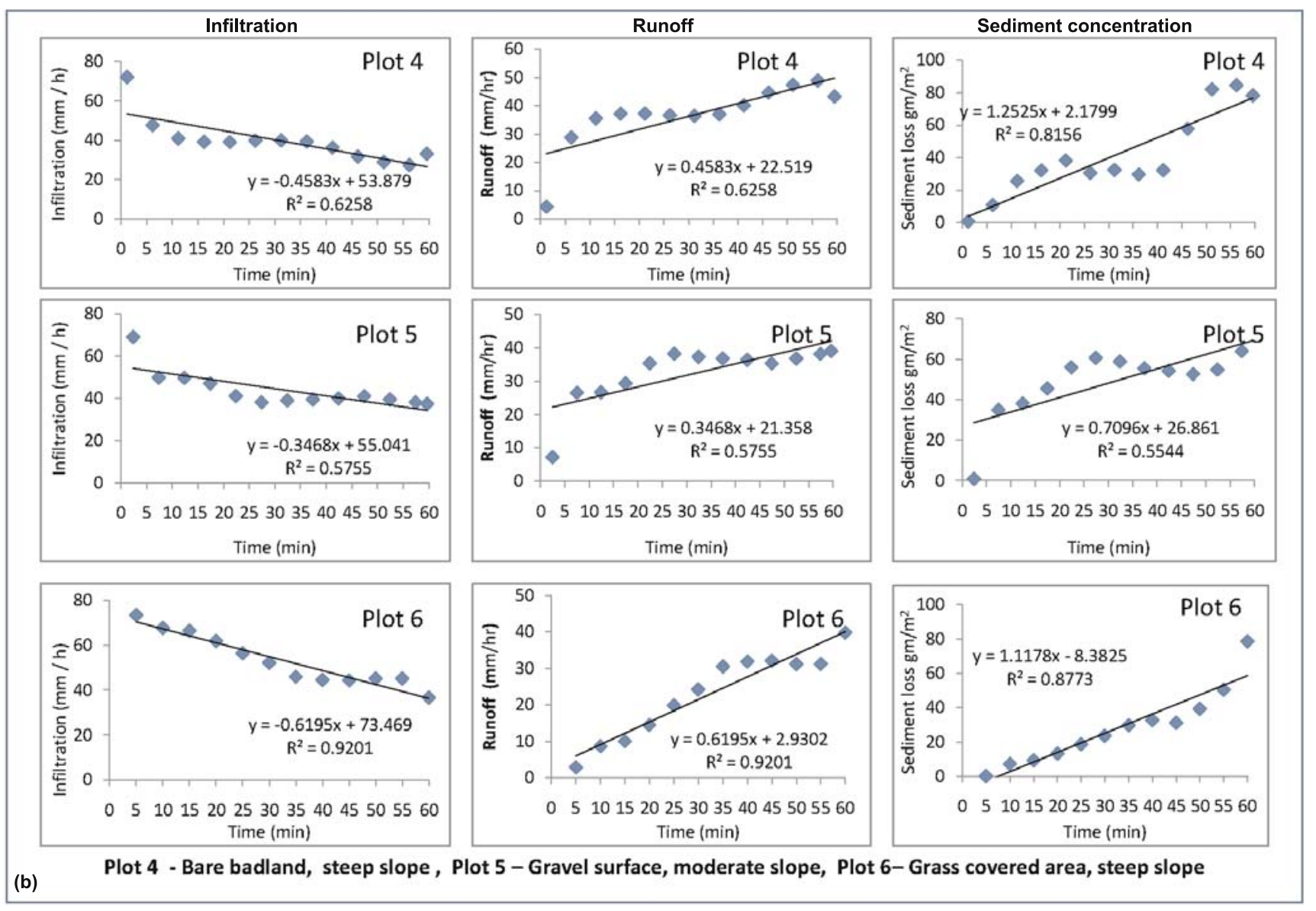

Figure 6. (Continued).

Table 2. Regression intercepts values of sediment yield, infiltration and run-off against time.

\begin{tabular}{|c|c|c|c|c|c|c|c|c|c|}
\hline & \multicolumn{3}{|c|}{ Time $(\min ) /$ sediment loss $\left(\mathrm{gm} / \mathrm{m}^{2}\right)$} & \multicolumn{3}{|c|}{ Time $(\min ) /$ infiltration $(\mathrm{mm} / \mathrm{h})$} & \multicolumn{3}{|c|}{ Time $(\min ) /$ run-off $(\mathrm{mm} / \mathrm{h})$} \\
\hline & $r^{2}$ & $a$ & $b$ & $r^{2}$ & $a$ & $b$ & $r^{2}$ & $a$ & $b$ \\
\hline 1 & 0.557 & 143.5 & 3.37 & 0.746 & 66.49 & -0.31 & 0.746 & 9.9 & 0.31 \\
\hline 2 & 0.909 & 8.355 & 0.69 & 0.822 & 62.89 & -0.39 & 0.822 & 13.5 & 0.39 \\
\hline 3 & 0.877 & -8.38 & 1.11 & 0.920 & 73.46 & -0.61 & 0.920 & 2.93 & 0.62 \\
\hline 4 & 0.815 & 2.179 & 1.25 & 0.625 & 53.87 & -0.45 & 0.625 & 22.5 & 0.46 \\
\hline 5 & 0.554 & 26.86 & 0.71 & 0.575 & 55.04 & -0.34 & 0.575 & 21.3 & 0.35 \\
\hline 6 & 0.815 & -4.15 & 0.29 & 0.949 & 77.14 & -0.38 & 0.949 & -0.7 & 0.39 \\
\hline
\end{tabular}

Sediment loss $(s)=a+b \times t$; Infiltration rate $(i)=c+f \times t$; Run-off $(r)=k+m \times t$; where, $b, f$ and $m$ are the rate of change in sediment loss gm $/ \mathrm{m}^{2}$, infiltration $(\mathrm{mm} / \mathrm{h})$ and run-off $(\mathrm{mm} / \mathrm{h})$ respectively as time changes. And $a, c$, and $k$ are the intercept value of sediment loss $\mathrm{gm} / \mathrm{m}^{2}$, infiltration rate $(\mathrm{mm} / \mathrm{h})$ and run-off $(\mathrm{mm} / \mathrm{h})$ respectively.

maintaining an equal surface cover as with the no-till system slightly increased interrill erosion. Removing residue on a no-till system, however, increased soil loss significantly.

Plot 4: This experimental plot represents true badland area, which is the dominant characteristic of the area. The plot is characterized by highly dissected bare surface with steep gradient of more than 50 degrees (figure 3a). The height of the four steel bars that support the rainfall simulator can be adjusted according to the slope of the land; hence the simulator could be placed firmly on such steep slopes. The dry and bare land with the steep slope yielded high run-off, with high sediment discharge. Out of the six experimental plots, this site displayed highest sediment yield. It is pertinent to mention here that this plot dominantly represents 


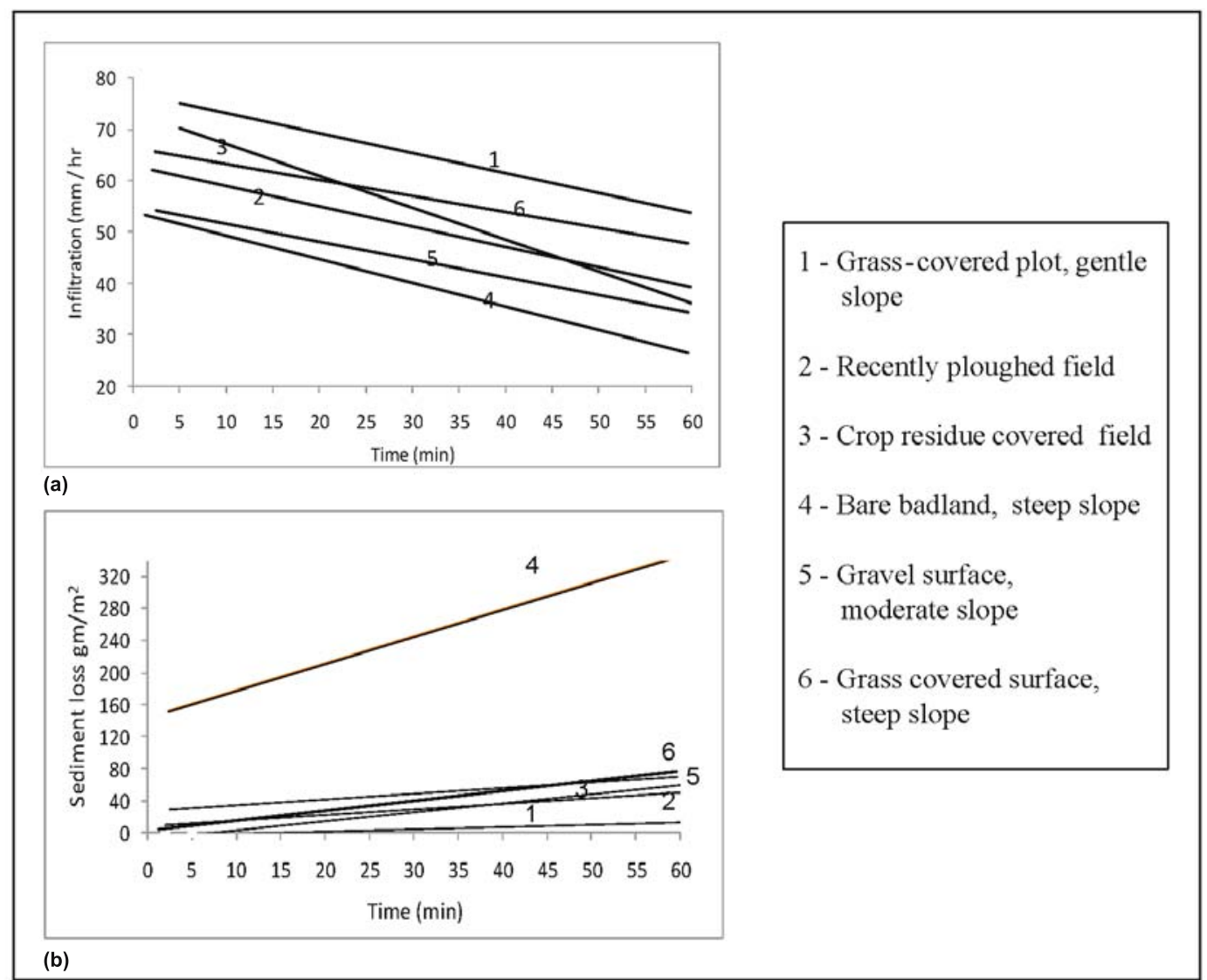

Figure 7. Infiltration against time (a) and sediment loss against time (b) after one hour experiment for all the six plots. Numbers between 1 and 6 indicate plots. Grass-covered area with 20 degree slope, shows highest rate of infiltration and lowest sediment concentration, whereas trend line no. 4 which bare badland, steep slope indicates stands as an outlier with lowest infiltration rate and highest sediment yield.

the characteristics of $2 / 3$ of the entire badland area in this part of the basin, and which could be categorized as the real high-risk zone with respect to soil erosion. The rate of the sediment yield, although variable, remained high throughout the experiment.

Plot 5: Badland surface covered with gravels is not uncommon in this site. One such surface was selected for this experiment. The slope of the surface is 22 degrees. The results indicate that the infiltration rate declines sharply within the first few minutes; however, high run-off was generated throughout the experiment. Though the overall sediment discharge was high, the run-off did not carry as much fines as expected. Both run-off and sediment discharge reached its peak at around $30 \mathrm{~m}$ and close to $60 \mathrm{~m}$, respectively. In between the runoff and sediment yield were steady.

Plot 6: The sixth plot is marked by $50^{\circ}$ slopes but is grass-covered. It took about 10 minutes for the run-off to be conveyed to the collection point. There was a distinct rise in the hydrograph around $35-40 \mathrm{~m}$. The run-off then reaches a plateau. The sediment yield remains low for a greater part of the experiment and displays a rise only after 40 minutes of the experimental run. The total sediment yield though high, is far less compared to Plot 4 with comparable slope but bare surface. This experiment demonstrates that the grasses successfully trap the sediments hence for a large part of the experiment, the yield remained low.

\section{Comparison of the plot results}

The combined regression plots of infiltration rate, run-off and sediment yield against time are given in figures 6 and 7, respectively. Infiltration shows negative relation with time for all the six experimental sites. Highest infiltration at the beginning was observed in Plot-1 where the surface is covered with grasses. Plot-6 with steep grass-covered slope shows the least change in infiltration rate with time. A noteworthy point is that the rate of change in infiltration rate is, more or less, comparable for all plots except Plot-3, which is the crop residue covered area. This plot demonstrates a highest rate of change. Run-off and sediment yield depict 
positive relation with time, as expected. The total run-off and sediment yield is highest from Plot-4 and least from Plot-1. The former is bare surface badland area with steep slope and the latter is grass-covered surface with gentle slope. Plot-3 again displays an anomalous trend because of its steeper regression slope.

Plot-wise regression lines for sediment yield reveal a very dissimilar trend. Of all the six plots, Plot-4, representing badland area with bare surface and steep slope, emerges as an outlier with highest intercept as well as regression slope. The sediment yield at the initiation of the experiment is an order of magnitude higher than all other experimental plots. This clearly demonstrates that the barren and steep surfaces are highly prone to erosion.

Another point that is worth consideration is that the grass-cover has a significant role to play in the sediment production rather than the slope angle as expected. This is demonstrated by comparison of Plot-4 and Plot-6 which have similar slope. However, unlike Plot-4 which is barren, Plot-6 is covered by grasses. The regression intercept is higher by an order of magnitude for Plot- 4 and the rate of change in sediment yield is higher than the latter (table 2). The intercept value $(a=9.9)$ for run-off is lower for Plot-4 than Plot-6 $(a=22.51)$. Plot-5, which is gravel covered surface with moderate slope, also shows higher sediment discharge than steeper but grass-covered slope of Plot-6 (table 2). An unmistakable conclusion that emerges from these comparisons is that grasses have an exceedingly important role to play in controlling sediment erosion.

\section{Discussion and conclusion}

Controlled experiments under simulated rainfall conditions have proved to be advantageous as these allow direct comparison of the responses of various land surfaces to same intensity rainfall. Under the controlled rainfall experiment, six plots with different slope and land cover revealed variations in infiltration, run-off and sediment yield response. Infiltration is highest for grasscovered area with gentle slope, and minimum for bare badland surfaces with steep slope. Run-off reveals an exactly opposite trend. In the initial period of the experiment, crop residue covered areas demonstrated high infiltration, but soon declined rapidly. Observations have shown that if the residue cover is below $90 \%$, it cannot provide full protection to the surface underneath. Ploughed field revealed moderate infiltration and later a gradual decline. Once again the effect of grasscover on infiltration and sediment removal could be seen which is represented by 6th regression line in figure 7(a and b). It shows relatively higher infiltration throughout in spite of the steeper gradient. Grass-cover protects the surface from soil erosion very effectively and wherever the grass-cover is absent the surfaces are highly prone to erosion. The bare badland surface with steep slope are especially highly susceptible to severe erosion. This finding gain considerable importance in view of the fact that over $2 / 3$ area is characterized by such bare and steep slopes.

Similar findings are also presented by Bhardwaj and Singh (1992) during their rainfall experiment study on plots with different characteristics. The authors found that soil loss due to splash erosion is maximum in the case of cultivated land due to loose and easily detachable soil particles, followed by bare land. The soil loss observed from grassed land is found to be 4, 5 and 5, 7 times lower than those measured from the bare and cultivated lands under rainfall intensities of $100 \mathrm{~mm} / \mathrm{h}$ and $200 \mathrm{~mm} / \mathrm{h}$, respectively. Splash erosion is also found to increase with the increase in rainfall intensity, although the increase is relatively small in the case of grassed land. Soil loss from grassed land is approximately 2, 6 and 2, 5 times lower than those measured from bare and cultivated lands under rainfall intensities of $100 \mathrm{~mm} / \mathrm{h}$ and $200 \mathrm{~mm} / \mathrm{h}$, respectively, for a period of 30 minutes.

During most time of the year, especially after monsoon, a large part of the badland surface is covered with grasses. In the later part of the year, these tall grasses become dry but still offer a protective cover on the surface. On the contrary, sediment yield is maximum from the badland slopes that have been stripped of grasses as well as from the ploughed fields. This further implies that if the badland slopes are undisturbed and are allowed it to remain under the natural condition of grass cover, the rate of sediment removal would have been remarkably reduced than what is occurring at present due to human activities in the region. Crop residue cover treatment, which is commonly practiced in this area, can provide a complete protection only for a short time that too with the percentage of the cover is $>90 \%$ (Faniran and Jeje 1983). Highest run-off as well as sediment yield, as expected, is generated from the bare badland slopes. Since severely dissected bare slopes (which are steadily increasing in area due to human activities recently) are more common in the region, the area under investigation warrants immediate attention of the concerned authorities.

\section{Acknowledgements}

We express our deep gratitude to $\mathrm{Mr}$ Yogesh Wani and Mr Rahul Pardeshi, MIT Engineering 
College, Pune, for the design and fabrication of the rainfall simulator. Mr Asaram Jadhav and Mr Vikas Nagare helped us during the field experiments. The authors express a very special thanks to Dr V S Kale, Professor in Geography, University of Pune for critically reviewing the paper and giving suggestions to improve the presentation of the paper.

\section{References}

Bhardwaj A and Singh R 1992 Development of a portable rainfall simulator infiltrometer for infiltration, runoff and erosion studies; Agricultural Water Management 22 235-248.

Bowyer-Bower T A S and Burt T P 1989 Rainfall simulators for investigating soil response to rainfall; Soil Technol. 2 $1-16$.

Bradford Joe M and Huang Chi-hua 1994 Interrill soil erosion as affected by tillage and residue cover; Soil Till. Res. 31 353-361.

Cerda A, Ibanez S and Calvo A 1997 Design and operation of a small and portable rainfall simulator for rugged terrain; Soil Technol. 11 163-170.

Dunne T, Dietrich W E and Brunengo M J 1980 Simple, portable equipment for erosion experiments under artificial rainfall; J. Agric. Engng. Res. 25 161-168.

Exeter N L 1990 Design and operation of a rainfall simulator for field studies of runoff and soil erosion; Soil Technol. 3 $385-397$.

Faniran A and Jeje L K 1983 Humid Tropical Geomorphology; Chapter on Removal Process in Humid Tropics Longman, New York, pp. 96-97.
Hignett C T, Gusli S, Cass A and Besz W 1995 An automated laboratory rainfall simulation system with controlled rainfall intensity, raindrop energy and soil drainage; Soil Technol. 8 31-42.

Hudson N W 1961 An introduction to mechanics of soil erosion under conditions of sub tropical rainfall; Proc. Trans. Rhod. Sci. Assoc. 49 15-25.

Kale V S and Rajaguru S N 1987 Late Quaternary alluvial history of the northwestern Deccan Upland region; Nature 325 612-614.

Rawat J S and Rai S P 1997 Pattern and intensity of erosion in the environmentally stressed Khulgad watershed, Kumaun Himalaya; J. Geol. Soc. India 50 331-338.

Rawat J S and Rawat M S 1994 Accelerated erosion and denudation in the Nana Kosi watershed, central Himalaya, India. Part I: Sediment Load; Mt. Res. Dev. $1425-38$.

Rawat J S, Haigh M M and Rawat M S 1992 Hydrological response of a Himalayan pine forest micro-watershed; Preliminary results; Proc. Int. Symp. on Hydrology of Mountainous Areas, Simla 28-30 235-258.

Roth C H, Meyer B and Frede H-G 1985 A portable rainfall simulator for studying factors affecting runoff, infiltration and soil loss; Catena 12 79-85.

Singh R, Panigrahy N and Philip G 1999 Modified rainfall simulator infiltrometer for infiltration, runoff and erosion studies; Agricultural Water Management $\mathbf{4 1}$ $167-175$.

Tricker A S 1979 The design of a portable rainfall simulator infiltrometer; J. Hydrol. 41 143-147.

Wright J A, Smith J, Gundry S W and Glasbey C A 2002 A spatial rainfall simulator for crop production modeling in southern Africa; Math. Comput. Model. 35 $1459-1466$. 